\author{
Asian Journal of \\ Medical and Biological Research \\ ISSN 2411-4472 (Print) 2412-5571 (Online) \\ www.ebupress.com/journal/ajmbr
}

\title{
Article \\ Socio-economic status and feeding practices among the mothers of under-five children in an urban slum of Bangladesh: a cross-sectional study
}

\author{
A.F.M. Sujauddoula Al Amin ${ }^{1 *}$, Sumon Chandra Debnath ${ }^{2}$, Asadullahil Galib ${ }^{3}$, Md Abdur Rouf ${ }^{4}$, Md. Ekramul \\ Haque $^{5}$, Md. Fazlay Rabby ${ }^{6}$, Taslima Zannat $^{7}$ and Zahidur Rahim ${ }^{8}$ \\ ${ }^{1}$ Nutrition Specialist, HCMP, BRAC, Cox's Bazar, Bangladesh \\ ${ }^{2}$ Senior Health Education Officer, Civil Surgeon Office, Chattogram, DGHS, MOHFW, GoB \\ ${ }^{3}$ Medical Officer, Upazila Health Complex, Ukhia, Cox's Bazar, Bangladesh \\ ${ }^{4}$ Assisant Director, Aichi Medical College and Hospital, Uttara, Dhaka, Bangladesh \\ ${ }^{5}$ Evaluator, CDC, DGHS, Mohakhali, Dhaka-1212, Bangladesh \\ ${ }^{6}$ Surveillance Medical Officer, CDC, DGHS, Mohakhali, Dhaka-1212, Bangladesh \\ ${ }^{7}$ Assistant Surgeon, Upazila Health Complex, Bhangura, Pabna, Bangladesh \\ ${ }^{8}$ Senior Project Officer, Save the Children, Dhaka, Bangladesh \\ *Corresponding author: A.F.M. Sujauddoula Al Amin, Nutrition Specialist, HCMP, BRAC, Cox's Bazar, \\ Bangladesh. Phone: +8801718-444254; E-mail: afmsuja@gmail.com
}

Received: 07 September 2018/Accepted: 27 September 2018/ Published: 30 September 2018

\begin{abstract}
Poor socio-economic conditions and inappropriate feeding practices in slum dwelling mothers can have adverse consequences for the health and nutritional status of their under-five children. The present study was to assess the feeding practices and socio-economic status mothers of under-five children. A cross-sectional study was conducted from January 2015 to December 2015 in four urban slums of Bangladesh. Two hundred and fifty five mother-child pairs were selected by non-random convenience sampling and were interviewed using a pre-tested questionnaire. Anthropometric measurements were taken from under-five children aged 6-59 months. In the present study, boys (54.0\%) were predominant over girls (46.0\%). The prevalence of initiation of breastfeeding after delivery, prelacteal feeds, exclusive breastfeeding and bottle-feeding were 34.5\%, 43.5\%, $39.6 \%$ and $30.6 \%$, respectively. Out of 255 children studied, more than half $(57.6 \%)$ of the children received complementary feeds at the appropriate time whereas $45.9 \%$ children received with appropriate consistency. Meal frequency was $40.4 \%$ and minimum dietary diversity was given to only $39.6 \%$ of the children. Minimum dietary diversity means feeding the child food from at least four food groups. Feeding practices improve as mother's education levels and household income status increases while maximum slum dwelling mothers are illiterate and primary level completed and household income status are not static. Data showed that overall $14.0 \%$ of under-five children were suffering from malnutrition. In terms of severity, $11.3 \%$ were moderately malnourished-MAM and $2.7 \%$ were severely malnourished-SAM. Various inappropriate feeding practices are more prevalent among urban slum mothers. From this study, it was evident that mothers of low socio-economic group have poor knowledge regarding the feeding practices of their under-five children. There is an urgent need to bridge the "knowledge gap" and "practice gap" of mother's from urban slum and lower socio economic strata of the community by further strengthening the on-going breastfeeding programme, breastfeeding knowledge and practice of mothers in urban slum areas.
\end{abstract}

Keywords: socio-economic status; feeding practices; under-five children; urban slum

\section{Introduction}

Optimal nutrition and proper feeding practices are imperative for healthy growth and development of infants and young children (Black et al., 2013; UNICEF, 2009). The time from womb to first 2 years of age (1000 days) regarded as "critical window period/windows of opportunity" owing to rapid growth and brain development that 
occurs in children during this period (WHO, 2008). Any damage to physical growth and brain development that occurs during this period is likely to be extensive and, if not corrected, irreversible (Hoddinott et al., 2013; Alderman et al., 2013). Hence, infant and young child feeding practices (IYCF) during this period play a critical role. Faulty breastfeeding and poor complementary feeding can lead to undernutrition (Srivastava and Sandhu, 2007; Garg and Chadha, 2009; Ma et al., 2012).

Bangladesh has made remarkable progress in many areas during the last two decades however there are still lagging when it comes to urban areas especially in terms of feeding practices and malnutrition among under-five children. Urban populations are diverse and varied, both economically and in terms of living conditions that affect health negatively (BUHS, 2013).

Urban slum dwellers are exposed to poor environmental conditions. In the Census of Slum Areas and Floating Population 2014 covering all city corporations revealed that the number of slums, households and population in the Khulna City Corporation which contains 1,134 slums, 20536 households and 79827 population in which 6669 were under-five children (BBS, 2015). Ignorance and difficult conditions of life in the slums are likely to result in improper food habits, low health care use and hygiene awareness and lack of knowledge of the origin of sickness and proper measures for the cure (Zunaid et al., 2017; Huq and Tasnim, 2008). Children living under such conditions are at especially high risk for health and nutritional problems. Inadequate knowledge about appropriate food and feeding practices is often a greater determinant of malnutrition than the lack of food (UN, 2014; Huq and Tasnim, 2008).

Bangladesh Demographic and Health Survey 2014 revealed that currently wasting or acute malnutrition affects $14 \%$ of Bangladeshi children, while one-third of children are also underweight, which is a composite of stunting and wasting (BDHS, 2014). The rates are equally debauched for urban Bangladesh, where half of the under-five children in slums were stunted, which is around one-third for non-slums. Underweight among under-five children in slums (43\%) is considerably higher in non-slums (26\%) and rest urban areas (30\%) (BUHS, 2013). This high proportion of malnutrition poses a threat to the overall progress of the country.

Appropriate feeding practice ranks first among the most effective interventions to improve child health and nutrition. However, some inappropriate breast feeding practices do exist both in rural and urban area of Bangladesh (Fakir and Khan, 2015). A slum dwelling mothers are generally not well educated; do not have better socioeconomic status and difficulty in accessing information regarding breast feeding as compared to their urban counter parts (Mittal et al., 2007; Fauveau et al., 1992). Those mother needs knowledge regarding these in order to practice them and that depends on the mother's education, her socioeconomic status, her access to information regarding breast feeding, feeding taboos, and so on (Srivastava et al., 2012; Mittal et al., 2007). As there is a paucity of literature on the appropriate feeding practices in the slum area. Therefore, the present study was undertaken to assess the socio-economic status and feeding practices of slum dwelling mothers and the nutritional status of under-five children.

\section{Materials and Methods}

\subsection{Study design and settings}

This cross sectional study was conducted in urban slum areas of Khulna City Corporation (KCC) with an aim to assess the socio-economic status and child feeding practices among the mothers in urban slum areas during the period of January to December 2015. For this study, 3 slums (Railway line, Daulatpur and Khalishpur) were selected randomly from the urban areas of KCC.

\subsection{Study participants and inclusion criteria}

All the mothers who had children aged 6 to 59 months included in the study based on the following criteria: willingness of mother to participate in the study, healthy children aged 6-59 months and children who were found to be ill or suffered from any illness in the previous three months were not included in this study. Two hundred and fifty five mother-child pairs aged 6 to 59 months who met the inclusion criteria were included in the study.

\subsection{Sample size and sampling}

A total of 255 mother's with their under-five children (6 to 59 months) who lived in three slums of KCC areas and who available during data collection period, were included as the sample of this study. Participants were selected through door-to-door visits using simple random sampling method. 


\subsection{Data collection technique}

Data were collected with data collection instruments with the help from pre-designed and semi-structured questionnaire. Two instruments were used: a semi-structured questionnaire besides anthropometric measurements. Initially mothers were informed about the study goals and verbal consent was obtained to take their child's anthropometric measurements. The questionnaire was used to interview the study participants to elicit the socio-economic information like religion, educational and occupational of the mothers, household members and income, family size and type, housing conditions, sanitary facilities, source of drinking water as well as information on age, gender and child's current feeding practices.

\subsection{Anthropometric measurements}

Mid-upper arm circumference (MUAC) was measured to the nearest $0.1 \mathrm{~cm}$ using a flexible, non-stretchable measuring tape. The MUAC is a quick and reliable method for screening children to identify those who are acutely malnourished (Velzrboer et al., 1983; Kaur et al., 2005). The MUAC cut-off score $\geq 12.5 \mathrm{~cm}$ was considered as 'Normally Nourished', $\geq 11.5-<12.5 \mathrm{~cm}$ was considered as 'Moderate Acute malnutrition (MAM)' and $<11.5 \mathrm{~cm}$ was considered as 'Severe Acute malnutrition (SAM)'. There are several practical and theoretical advantages of using MUAC rather than weight-for-height for the determination of nutritional status of the under-five children (Myatt et al., 2006).

\subsection{Data processing and analysis}

Data were collected on the paper forms simultaneously entered into SPSS version 20. Data were checked and cleaned for completeness and consistencies thereafter coded, recoded according to the aim and objective of the study. The results were organized, summarized and presented using appropriate descriptive measures such as text, tables, graphs, frequencies and percentage.

\subsection{Ethical issues}

Ethical clearance taken from ethical committee of State University of Bangladesh. Informed verbal consent obtained from each of the study participant after explaining the aims of the study. Individual participant records were coded on each respective questionnaire and confidentiality was maintained at all levels of the study.

\section{Results}

\subsection{Sample characteristics of the study}

In the present study, maximum (66.0\%) of the children belong to $24-59$ months followed by $21.0 \%$ between 12 23 months and $13.0 \%$ between 6-11 months. More than half (54.0\%) of the children were boys whereas $46.0 \%$ children were girls (Table 1).

Table 2 showed the socio-economic status of the mothers. About half (47.5\%) of the mother's had single underfive child while $52.5 \%$ mother had more than two under-five children. The maximum of the mothers belongs to Muslims religion (73.4\%) as compared to Hindus (14.1\%). Among the total 255 mothers, about one-third (32.2\%) mothers were illiterate while $44.3 \%$ of mothers had attended primary education, $19.2 \%$ mothers had attended secondary level education and only $4.3 \%$ slum dwelling mothers were passed SSC and above. However, only few mother were the working $(13.7 \%)$ mother and the maximum $(86.3 \%)$ were homemakers. More than half (59.2\%) of the mothers belonged to the income group of BDT 6001-12000 whereas only 9.4\% mothers belonged to BDT $\geq 12000$ (Table 2).

Out of 255 mothers, about two-third (65.5\%) belonged to the nuclear family and the highest percentage of the mothers were living in Kutcha/Tin-built (66.3\%) followed by Semi-pucca (24.7\%), Jhupri (4.7\%) and Pucca $(4.3 \%)$. About three-fourth $(65.5 \%)$ of the households were getting their drinking water from tap water and the rest $(34.5 \%)$ of the households were getting from tube-well. The present study revealed that the one-fourth $(24.3 \%)$ of the households were using sanitary latrine whereas the maximum $(75.7 \%)$ were not using sanitary latrine (Table 2).

\subsection{Nutritional status}

The present study analyzed the nutritional status of the under-five children based on MUAC classification. The maximum $(86.0 \%)$ study children normally nourished whereas $11.0 \%$ were moderately malnourished (MAM) and $2.7 \%$ children severely malnourished (SAM) (Table 3 ). 
3.3. Feeding Practices of mothers of under-five children

The current study analyzed different indicators of child feeding practices. In this study about one-third (34.5\%) of the mothers breastfed their child within 1 hour after birth whereas $43.5 \%$ mothers have given prelacteal feeds to their child during the first three days of life. The prevalence of exclusive breastfeeding of infants up to age 6 months was $60.4 \%$ hence the prevalence of bottle-feeding practice was $30.6 \%$ (Table 4).

Among the total 255 participants, more than half $(57.6 \%)$ of the mothers have initiated complementary foods at appropriate time in which $39.6 \%$ of mothers have given complementary foods of appropriate diversity of food, $45.9 \%$ have given at appropriate consistency, $40.4 \%$ have given appropriate frequency and $38.0 \%$ of mothers have given complementary foods at appropriate quantity.

The present study found that more than half $(51.8 \%)$ of the mothers practiced 'responsive feeding' whereas about one-third $(36.5 \%)$ of mothers feed their child forcibly followed by $27.8 \%$ rewarding their child for feeding (Table 4).

Table 1. Profile of the under-five children [ $n=255]$.

\begin{tabular}{lll}
\hline Variables & n & \% \\
\hline Age group & & \\
6-11 months & 34 & 13.0 \\
12-23 months & 54 & 21.0 \\
24-59 months & 167 & 66.0 \\
Gender & & \\
Boys & 139 & 54.0 \\
Girls & 116 & 46.0 \\
\hline
\end{tabular}

Table 2. Socio-economic status of the mothers [ $n=255]$.

\begin{tabular}{|c|c|c|}
\hline Variables & $\mathbf{n}$ & $\%$ \\
\hline \multicolumn{3}{|l|}{ No of under 5 children } \\
\hline Single & 121 & 47.5 \\
\hline$\geq$ Two & 134 & 52.5 \\
\hline \multicolumn{3}{|l|}{ Religion } \\
\hline Muslim & 219 & 85.9 \\
\hline Hindus & 36 & 14.1 \\
\hline \multicolumn{3}{|l|}{ Educational status } \\
\hline Illiterate & 82 & 32.2 \\
\hline Primary (I-V) & 113 & 44.3 \\
\hline Secondary (VI-X) & 49 & 19.2 \\
\hline SSC and above & 11 & 4.3 \\
\hline \multicolumn{3}{|l|}{ Working status } \\
\hline Nonworking (Homemakers) & 177 & 69.4 \\
\hline Working (Maidservant) & 78 & 30.6 \\
\hline \multicolumn{3}{|l|}{ Household income (in Taka) } \\
\hline$\leq 6000$ & 80 & 31.4 \\
\hline $6001-12000$ & 151 & 59.2 \\
\hline$\geq 12000$ & 24 & 9.4 \\
\hline \multicolumn{3}{|l|}{ Family types } \\
\hline Nuclear & 167 & 65.5 \\
\hline Joint & 88 & 34.5 \\
\hline \multicolumn{3}{|l|}{ Housing conditions } \\
\hline Jhupri & 12 & 4.7 \\
\hline Katcha/Tin-built & 169 & 66.3 \\
\hline Semi-pucca & 63 & 24.7 \\
\hline Pucca & 11 & 4.3 \\
\hline \multicolumn{3}{|l|}{ Sanitation facilities } \\
\hline Sanitary latrine & 62 & 24.3 \\
\hline Non sanitary latrine & 193 & 75.7 \\
\hline \multicolumn{3}{|l|}{ Drinking water source } \\
\hline Tube-well water & 88 & 34.5 \\
\hline Tap water & 167 & 65.5 \\
\hline
\end{tabular}


Table 3. Nutritional status of the children by MUAC classification [ $n=255]$.

\begin{tabular}{lll}
\hline MUAC $(\mathbf{c m})$ & $\mathbf{n}$ & $\mathbf{\%}$ \\
\hline $\begin{array}{l}\text { Normal } \\
(\geq 12.5 \mathrm{~cm})\end{array}$ & 219 & 86.0 \\
$\begin{array}{l}\text { Moderate Acute malnutrition (MAM) } \\
(\geq 11.5-<12.5 \mathrm{~cm})\end{array}$ & 29 & 11.3 \\
$\begin{array}{l}\text { Severe Acute malnutrition (SAM) } \\
(<11.5 \mathrm{~cm})\end{array}$ & 7 & 2.7 \\
Total & 255 & 100.0 \\
\hline
\end{tabular}

Table 4. Feeding Practices of mothers of under-five children [ $n=255]$.

\begin{tabular}{|c|c|c|}
\hline Variables & $\mathbf{n}$ & $\%$ \\
\hline \multicolumn{3}{|c|}{ Early initiation of breastfeeding } \\
\hline Yes & 88 & 34.5 \\
\hline No & 167 & 65.5 \\
\hline \multicolumn{3}{|c|}{ Prelacteal feeds } \\
\hline Yes & 111 & 43.5 \\
\hline No & 144 & 56.5 \\
\hline \multicolumn{3}{|c|}{ Exclusive breastfeeding } \\
\hline Yes & 101 & 39.6 \\
\hline No & 154 & 60.4 \\
\hline \multicolumn{3}{|c|}{ Bottle feeding } \\
\hline Yes & 78 & 30.6 \\
\hline No & 177 & 69.4 \\
\hline \multicolumn{3}{|c|}{ Timely initiation of complementary feeding } \\
\hline Yes & 147 & 57.6 \\
\hline No & 108 & 42.4 \\
\hline \multicolumn{3}{|c|}{ Diversity of food } \\
\hline Yes & 101 & 39.6 \\
\hline No & 154 & 60.4 \\
\hline \multicolumn{3}{|c|}{ Consistency of food } \\
\hline Yes & 117 & 45.9 \\
\hline No & 138 & 54.1 \\
\hline \multicolumn{3}{|c|}{ Frequency of feeding } \\
\hline Yes & 103 & 40.4 \\
\hline No & 152 & 59.6 \\
\hline \multicolumn{3}{|c|}{ Quantity of food } \\
\hline Yes & 97 & 38.0 \\
\hline No & 158 & 62.0 \\
\hline \multicolumn{3}{|c|}{ Responsive/ demand feeding } \\
\hline Yes & 132 & 51.8 \\
\hline No & 123 & 48.2 \\
\hline \multicolumn{3}{|c|}{ Force feeding } \\
\hline Yes & 93 & 36.5 \\
\hline No & 162 & 63.5 \\
\hline \multicolumn{3}{|c|}{ Apprehension for feeding } \\
\hline Yes & 71 & 27.8 \\
\hline No & 184 & 72.2 \\
\hline
\end{tabular}

\subsection{Discussion}

The current cross-sectional study was conducted with an aim to determine the socio-economic status and child feeding practices among the mothers of under-five children. Mothers having children of age 6 to 59 months residing in low socioeconomic area and urban slum areas of Khulna City Corporation (KCC) city were included in the study.

The present study revealed that $66.0 \%$ of the children belonged to group of $24-59$ months, $21.0 \%$ to $12-23$ months and only $13.0 \%$ of the children belonged to group of 6-11 months. These findings were consistent with the study done in Bangladesh by Hoque et al., 2016. Halder, 2000 conducted a study in Bangladesh in which boys and girls were 59.0\% and 41.0\%. According to Census of Slum Areas and Floating Population 2014, the 
male and female were $51.2 \%$ and $48.0 \%$, which was almost similar to our present study where the percentage of male and female were $54.0 \%$ and $46.0 \%$.

The present study stated that the maximum of the mothers belongs to Muslims religion (73.4\%) as compared to Hindus (14.1\%). Information on religious affiliations of slum dwellers was collected in the Census of Slum Areas and Floating Population 2014. The percentage of Muslim people was the highest (92.7\%) in comparison with other religions. These findings are comparable to the current study where Muslim slum dwellers also dominant over other religions.

The present cross-sectional study stated that $44.3 \%$ of slum dwelling mothers had attended primary education while $32.2 \%$ mothers were illiterate, $19.2 \%$ mothers had attended secondary level education and only $4.3 \%$ slum dwelling mothers were passed SSC and above. Mothers or caregivers in slums are less likely to have higher levels of education and our finding was similar to an earlier observation (Hoque et al., 2016). However, 30.6\% mothers were belonging to the maidservant and the maximum (69.4\%) were homemakers/housewife. The above findings are consistent with the Census of Slum Areas and Floating Population 2014 in which 25.0\% mothers were belonging to maidservants.

The present study concluded that about two-third (65.5\%) belonged to the nuclear family and the highest percentage of the mothers were living in Kutcha/Tin-built (66.3\%) followed by Semi-pucca (24.7\%), Jhupri (4.7\%) and Pucca (4.3\%). It was evident from the slum census 2014 that the highest percentage of dwelling units are Kutcha/Tin-built (62.45\%) followed by semi-pucca $26.4 \%$ and Jhupri (6.5\%). The socio-economic development of a country has direct bearing on housing condition and household facilities of the people. The housing structures within slum areas are made of relatively cheaper materials like straw, leaves, polythene sheets, wood, bamboo, coarse papers etc.

In our present study about three-fourth $(65.5 \%)$ of the households were getting their drinking water from tap water and the rest $(34.5 \%)$ of the households were getting from tube-well. There was a discrepancy between our findings and the slum census 2014.

The present study revealed that the one-fourth $(24.3 \%)$ of the households were using sanitary latrine whereas the maximum (75.7\%) were not using sanitary latrine. Our findings are very most consistent with Census of Slum Areas and Floating Population 2014 wherein the highest percentage of households using non-sanitary latrine (75.7\%) followed by sanitary latrine $(26.3 \%)$, hanging/Kutcha $(8.6 \%)$ and other/open space $(1.8 \%)$ at the national level.

The current study assessed the nutritional status of 255 under-five children with standard anthropometric indices based on MUAC classification. The results of this study showed a quiet high level of undernutrition (14.0\%) among under-five children living in urban slums, and this finding coincides with other studies in Bangladesh (BDHS, 2014; Sadler et al., 2011). The present study findings are similar to another study conducted by Dasgupta et al., 2015 among under-five children in a slum of West Bengal, India.

In the present study, initiation of breastfeeding within one hour after delivery occurred only in one-third of the children. This observation is supported by a study carried out by Gupta et al., 2010 in urban slum of Lucknow which revealed that only $36.6 \%$ mothers initiated breast feeding within one hour after of delivery and most common reasons given for delayed initiation were family custom/belief, no secretion of breast milk, and discomfort in the mother. A study from Mumbai (Parekh et al., 2004) showed that $82.3 \%$ of infants were breastfed within four hours of birth that is much more higher compared to our study. The current study observed that about $43.5 \%$ mothers in a slum area gave prelacteal feeds. On the contrary, in a study done by Qiu et al., 2008 as many as $62.0 \%$ mothers in urban area and $39.0 \%$ mothers in rural area gave prelacteal feeds.

The present study identified that the prevalence of exclusive breastfeeding is about $40.0 \%$. However, the prevalence of exclusive breastfeeding recorded in this study was lower compared to the national prevalence reported in the BDHS, 2014. This difference might be due to variations in socio cultural aspects among study participants. This is in contrast to the study done by Aggarwal et al., 2006 at Delhi where in 50.0\% of the mothers had practiced exclusive breastfeeding till 6 months. This difference may be due to the good educational status in the above study whereas in this study there were $32.2 \%$ of the mothers who were illiterate. A study done in urban slum of Kolkata by Roy et al, 2009 found that exclusive breastfeeding rate at 4 months was $61.3 \%$. Data from urban slums and resettlement colonies repeatedly documented that although the breastfeeding was very common, exclusive breastfeeding was practiced only in $30-40 \%$ of infants younger than 4 months of age (Aneja et al., 2001).

The proportion of bottle-feeding (30.6\%) in the present study was comparable with results of a study by Wamani et al., 2005 however, less than the reported by Pandey et al., 1995 from rural West Bengal, India. The present study revealed that $57.6 \%$ mothers have complementary feeding whereas $39.6 \%, 45.9 \%, 40.4 \%$ and 
$38.0 \%$ of mothers have practiced with appropriate diversity, consistency, frequency and quantity, respectively. Responsive and force-feeding practiced by $51.8 \%$ and $36.5 \%$ of mothers, respectively.

A study in Bangladesh documented that the frequency, amount, energy density, and diversity of food remained important issues in complementary feeding. Though demand feeding which actively involves the infant in controlling the breast-milk intake is desirable, only $51.8 \%$ of slum dwelling mothers practiced it. A study on infant feeding practices by Parekh et al.2004 in India showed that feeds were given on demand by as many as $73.7 \%$ mothers and yet another study by Panda et al, 2008 in Cuttack showed that $90.1 \%$ of mothers fed their infants on demand. It has been observed that slum mothers were more active and working hard compared to the others. Hence, probably it was not possible for them to practice scheduled feeding as done by slum mothers. Apprehension among the slum mothers regarding the growth of their child may also be the reason for their time bound feeding.

\section{Conclusions}

The findings of the present study confirm that various inappropriate breast-feeding practices are more prevalent among mothers of urban slum. Many persons around the mothers/caregivers influence them a lot. Educational qualification of parents especially mothers has little positive role. Early and late initiations are due to some misconceptions. Bottle feeding, fast foods and lack of proper family support are the most important barriers of appropriate complementary feeding practices followed by pre-lacteal feeding, formula feeding, commercial cereal, feeding during sleep and negative attitude of mothers/caregivers. This study advocates the need for future research that focuses on slum areas on a larger scale to the usefulness of appropriate feeding practices of mothers of under-five children. Repeated counseling starting from antenatal visits must change attitude of mothers/caregivers. Whole slum community should be motivated and involved actively. Government organizations and NGOs along with mass media should be utilized more vigorously for awareness building.

\section{Acknowledgement}

We are grateful to the hospital authority for the permission to conduct the study. We would like to thank all the study participants who added an extensive contribution during data collection.

\section{Conflict of interest}

None of declare.

\section{References}

Aggarwal A, S Verma, MMA Faridi and Dayachand, 2006. Complementary feeding: Reasons for inappropriateness in timing, quantity and consistency. Indian J. Pediatr., 75: 49-53.

Alderman H, L Elder, A Goyal, A Herforth, YT Hoberg and A Marini, 2013. Improving nutrition through multisecotoral approaches. Washington, DC: World Bank; 2013.

Aneja B, P Singh, M Tandon, P Pathak, C Singh and U Kapil, 2001. Etiological factor of malnutrition among infants in two urban slums of Delhi. Indian Pediatr., 38: 160-5.

BBS, 2015. Census of Slum Areas and Floating Population 2014. Bangladesh Bureau of Statistics (BBS), Statistics and Informatics Division, Ministry of Planning, Dhaka.

BUHS, 2013. Final Report. Dhaka, Bangladesh and Chapel Hill, North Carolina, USA: NIPORT, icddr,b and MEASURE Evaluation; 2015.

BDHS, 2014. NIPORT, Mitra and Associates, and ICF International Dhaka, Bangladesh and Calverton, Maryland, USA, 2016.

Black RE, LH Allen, ZA Bhutta, LE Caulfield, M de Onis, M Ezzati, C Mathers, J Rivera, Maternal and Child Undernutrition Study Group, 2008. Maternal and child undernutrition: global and regional exposures and health consequences. Lancet, 371: 243-260.

Black RE, CG Victora, SP Walker, ZA Bhutta, P Christian and M De Onis, 2013. Maternal and child undernutrition and overweight in low-income and middle-income countries. Lancet, 382: 427-51.

Dasgupta A, SK Sahoo, P Taraphadar, PS Preeti, D Biswas, A Kumar and I Sarkar, 2015. Composite index of anthropometric failure and its important correlates: a study among under-5 children in a slum of West Bengal, India. International Journal of Medical Science and Public Health, 4: 414-419.

Fakir AM and MW Khan, 2015, Determinants of malnutrition among urban slum children in Bangladesh. Heal. Econ. Rev., 5: 112.

Fauveau C, M Siddiqui, A Briend, R Silimperi, N Begum and V Fauveau, 1992. Limited impact of a targeted food supplementation program in Bangladesh urban slum children. Ann. Trop. Pediatr., 12: 41-6. 
Garg A and R Chadha, 2009. Index for measuring the quality of complementary feeding practices in rural India. J. Health Popul. Nutr., 27: 763-771.

Gupta P, V Srivastava, V Kumar, S Jain, J Masood, N Ahmad and JP Srivastava, 2010. Newborn care practices in urban slum of Lucknow City, UP. Indian J. Community Med., 35: 82-85.

Halder B, 2000. A study on Nutritional Status of Under 5 Children of Class III\&IV Employees of Army in Dhaka cantonment, Dhaka IPGM \&R, 38-55.

Hoddinott J, H Alderman, JR Behrman, L Haddad and S Horton, 2013. The economic rationale for investing in stunting reduction. Matern. Child Nutr., 9: 69-82.

Hoque MA, MA Sayeed, MR Ahsan, MAA Mamun and F Salim, 2016, Nutritional Status among under-5 Children of a selected slum in Dhaka city. Northern International Medical College Journal, 7: 143-145.

Huq MN and T Tasnim, 2008. Maternal Education and Child Healthcare in Bangladesh. Matern. Child Health J., 12: 43-51.

Kaur G, HS Kang, P Singal and SP Singh, 2005. Nutritional status: anthropometric perspective of preschool children. Anthropologist, 7: 99-103.

Ma J-Q, L-L Zhou, Y-Q Hu, J-R Liu, S-S Liu, J Zhang and XY Sheng, 2012. A summary index of infant and child feeding practices is associated with child growth in urban Shanghai. BMC Public Health, 12: 568.

Mittal A, J Singh and SK Ahluwalia, 2007. Effect of maternal factors on nutritional status of 1-5-year-old children in urban slum population. Indian J. Community Med., 32: 264-267.

Myatt M, T Khara and SA Collins, 2006. Review of methods to detect cases of severely malnourished children in the community for their admission into community best therapeutic care programs. Food and Nutr. Bull., 27: S7-S23.

Panda M, K Kar and B Mohapatra, 2008. Infant feeding practices of urban mothers. Am. J. Clin. Nutr., 87: $1852-1859$.

Pandey GK, S Hazra, A Vajpayee and P Chatterjee, 1997. Breastfeeding indicators from a rural community in West Bengal. Ind. J. Public Health, 41:71-74.

Parekh C, SB Bavdekar and V Shaharao, 2004, Study of infant feeding practices: factors associated with faulty feeding. J. Trop. Pediatr., 50: 306-308.

Qiu L, Y Zhao, CW Binns, AH Lee and X Xie, 2008. A cohort study of infant feeding practices in city, suburban and rural areas in Zhejiang Province, PR China. Int. Breastfeed J., 3: 4

Roy S, A Dasgupta and B Pal, 2009. Feeding practices of children in an urban slum of Kolkata. Indian J. Community Med., 34: 362-363.

Sadler K, C Puett, G Mothabbir and M Myatt, 2011. Community case management of severe acute malnutrition in southern Bangladesh. Medford, MA: Feinstein International Center; 2011.

Srivastava DN and A Sandhu, 2007. Index for measuring child-feeding practices. Indian J. Pediatr., 74: 363368.

Srivastava A, SE Mahmood, PM Srivastava, VP Shrotriya and B Kumar, 2012. Nutritional status of school-age children-A scenario of urban slums in India. Arch. Public Health, 70: 1.

UNICEF, 2009. Tracking Progress on Child and Maternal Nutrition: A Survival and Development Priority. New York, USA: UNICEF; 2009.

United Nations, 2014. World urbanization prospects: the 2014 revision highlights. New York: Population Division, United Nations Department of Economic and Social Affairs; 2014.

Velzrboer MI, BJ Selwyn, F Sargent, E Pollitt and H Delgado, 1983. The use of arm circumference in simplified screening for acute malnutrition by minimally trained health workers. J. Trop. Pediatr., 29: 159-166.

Wamani H, AN Astrom, S Peterson, T Tylleskar and JK Tumwine, 2005. Infant and young child feeding in western Uganda: knowledge, practices and socio-economic correlates. J. Trop. Pediatr., 51: 356-361.

World Health Organization, 2008. Indicators for assessing Infant and Young Child feeding practices: Conclusion of a census meeting held 6-8 November 2007. Washington DC: World Health Organization, 2008.

Zunaid AK, SE Arifeen, A Al-Mamun, SH Khan and N Chakraborty, 2017. Effects of individual, household and community characteristics on child nutritional status in the slums of urban Bangladesh. Arch. Public Heal., 75: 9. 